\title{
Intermitências da razão
}

\author{
Maria Helena Serôdio
}

Num tempo que, como todos os outros, só pode ser vivido como nostalgia, a cultura converteu-se na sua própria utopia. É assim que ela pseudovive na era da mundialização. Eduardo Lourenço

É com a implacável (mas compadecida) lucidez e o fascinante brilho argumentativo que todos the reconhecem que Eduardo Lourenço anatomiza - no livro de que retirei a epigrafe - as formas de esplendor do caos em que vivemos sem que, estranhamente, nos acometa qualquer sobressalto ou pânico intelectual. Aponta ainda para a simulação de ausência (ou denegação, e consequente invisibilidade) a que procede o novo tipo de poder que enquadra esta nossa "era do indivíduo", ao mesmo tempo que desvenda na culturização universal (do reino da telecracia) uma feérie que é puramente da ordem do decorativo e do fantasmagórico, apresentando o "mundo" como um imenso parque de atracções planetário, "uma realidade em segundo grau, por essência anestesiada, cortada de qualquer laço credivel com a realidade-poder donde emana"2.

No tecido de pluralidade de ordens - também no campo da cultura - a que conferimos equitativa legitimidade (por parecer inviável localizar um centro ou definir um indício no horizonte que possamos referir como um credivel ponto de fuga), o teatro surge como um dos possíveis, sem que se intrometa qualquer tentativa de hierarquizar procedimentos artísticos ou formas de vivência social comunitária que o possam promover, conferir-Ihe realce ou nele reconhecer o seu especifico valor cultural (superlativo, na minha opinião). E o teatro entra, por isso mesmo, na "regulação" que questões como o sucesso ou o arbitrário do jogo podem instituir. É assim que se oferece como intervenção de alcance minorado, dependendo (não só, mas em grande medida) das possibilidades financeiras de companhias ou instituições de programação de espectáculos para pagarem publicidades visíveis, ou para galvanizarem - por motivos que até podem ser aleatórios - os meios de comunicação para que anunciem ou prestem atenção ao que se apresenta em cena ou ao que se escreve e faz em torno do teatro.

Assim a rasura - ou menorização - pública de algumas iniciativas no campo do teatro pode entrar nesse incerto arbitrio e justificar-se quer pelas imponderabilidades previsíveis da saturação informativa, quer pela suspeita de que é limitada (em várias acepções) a "comunidade interpretativa" constituída pelos fazedores e públicos de teatro em Portugal.

Não foi, entretanto, tão noticiado como gostaríamos o Prémio da Crítica, bem como as Menções Especiais que a Associação Portuguesa de Críticos de Teatro atribuiu relativamente ao que se fez em teatro em 2005, nem a sessão pública da entrega - no Palácio Foz, em Lisboa, a
27 de Março - mereceu o destaque noticioso ou a afluência que a qualidade do que se premiava amplamente merecia. Mas no que toca à nossa razão de atribuirmos essas distinções, como escreve aqui neste número da revista Paulo Eduardo Carvalho, "continuamos a acreditar na sua pertinência e validade", apesar destas e de muitas outras dificuldades que enfrentamos para levar a cabo a sua publicitação. É para nós uma forma de ampliarmos e modalizarmos o campo, não apenas inserindo critérios de valor na apreciação do que se fez (dai a pertinência de justificarmos publicamente a razão dos galardões), mas também avivando a memória que a evanescência desta arte e o tumulto das muitas coisas de que se fala - na tal feérie atrás referida - tendem a esquecer ou a elidir.

Por outro lado, e mesmo admitindo que este é um combate pela utopia em que se converteu a "cultura" numa esfera possivel da sua praticabilidade, não podemos deixar de enaltecer o esforço e o valor de muitos dos que trabalham nas artes performativas em Portugal, sobretudo, porque trabalham em condições precárias, sujeitos a decisões frequentemente casuísticas e avulsas da tutela responsável. Algumas vezes por critérios insondáveis, outras por processos ínvios, quase sempre sem um rumo que seja claro nas razões maiores que as poderiam mover.

Julgamos ainda importante que os críticos queiram comprometer-se publicamente com a celebração do que de bom se fez em teatro, ainda que saibamos que nem tudo pôde ser devidamente apreciado, pelo evidente desajuste entre a pulverização do que existe (em termos de dispersão geográfica e da brevidade de tantas iniciativas) de encontro às limitadas possibilidades que nos impedem de tudo vermos e avaliarmos. E este nosso compromisso assumiu um especial relevo neste ano (para quem quisesse ou soubesse medir verdadeiramente o seu alcance e valor) justamente porque outros prémios de teatro que existiam entre nós - o Prémio Almada e o Prémio Ribeiro da Fonte (ambos atribuídos pelo Instituto das Artes) e o Prémio ACARTE - foram este ano descontinuados.

Mas se esta forma de cultura - ainda que inventada na sua própria utopia - parece ver reduzido o seu campo de visibilidade pelo menos em Portugal, não deixa de ser reconfortante constatar que o Prémio Nobel da Literatura em 2005 foi atribuido a um homem de teatro - Harold Pinter -, e que, entre nós, o Prémio Pessoa finalmente distinguiu um criador teatral, decerto um dos que mais indiscutivelmente o merece: Luis Miguel Cintra. Nestas duas muito especificas intermitências da razão - de que
'Eduardo Lourenço, O esplendor do caos, Lisboa, Gradiva, 1999, p. 24. 
quero falar neste editorial - não deixa de ser um pormeno curioso verificar que o primeiro texto de reflexão crítica sobre teatro que Luís Miguel Cintra publicou na imprensa periódica foi em 1968 (quando tinha apenas dezoito anos de idade) na revista 0 tempo e o modo (n. ${ }^{\circ}$ s 57/58, de Fevereiro-Março, pp. 274-278), e recenseava justamente dois espectáculos encenados em Portugal a partir de textos de Harold Pinter: Feliz aniversário, encenado por Artur Ramos, e 0 porteiro, encenado por Jorge Listopad. Estes prémios que Pinter e Cintra receberam em 2005 celebram afinal, o reencontro - ainda que simbólico - de dois excepcionais criadores de teatro. E falando de distinções a gente de teatro, é de sublinhar ainda que a medalha Goethe de 2006 foi atribuida pelo governo da Alemanha à tradutora e dramaturgista Vera San Payo de Lemos, que a recebeu em Weimar, pelo seu trabalho continuado de tradução, estudo e divulgação entre nós de autores alemães.

Como está convencionado relativamente ao número desta nossa revista que sai em Junho, o seu "Dossiê temático" expõe as razões que levaram o júri da Associação Portuguesa de Críticos de Teatro a atribuir o Prémio e as Menções Especiais relativos ao ano anterior, aqui trazidas pelos depoimentos de Paulo Eduardo Carvalho, Sebastiana Fadda, João Carneiro e pelo meu próprio.

Fazendo entretanto convergir o teatro que passou pelos palcos portugueses com o centenário que neste ano se celebra do nascimento de Samuel Beckett, o "Portefólio" reúne um vasto conjunto de fotografias de espectáculos sobre textos do nobelizado autor irlandês e lista - de forma exaustiva e por ordem cronológica - as encenações de Beckett que foram apresentadas em Portugal, num trabalho de grande rigor documental conduzido por Rui Pina Coelho e Sebastiana Fadda. Em "Notícias de fora" chega-nos circunstanciado relato do que em Turim se fez em Março passado em torno do Prémio Europa de Teatro (atribuido a Harold Pinter: outro sinal das intermitências de que falo) e do Congresso da Associação Internacional de Críticos de Teatro. E nos olhares cruzados, de que estas "Notícias" também dão testemunho, cabem ainda artigos sobre o teatro latino em Nova lorque; o que se pôde ver em Montréal, Quebeque, no âmbito do Congresso e Festival das Artes para a Juventude; e a perspectiva que um ocidental pode ter do teatro que se faz hoje na Coreia (aqui pela escrita de Patrice Pavis). E será ainda como visitação do que de lá fora nos pode entrar pelo nosso mundo adentro - intermitência proveitosa da equívoca globalização - que Catarina Maia nos fala de Mathew Barney na rubrica "Em rede".

Os "Estudos aplicados" combinam uma reflexão critica sobre a obra de Fernando Amado, uma breve incursão sobre textos de Beckett e uma interpelação satírica sobre algumas das desrazões de que, no entender de Guillermo Heras, parecem padecer alguns dos festivais internacionais para a todo o custo cumprirem a "feérica" "culturização" mundial de que fala Eduardo Lourenço. A análise de algumas produções teatrais portuguesas que se incluem nos "Passos em volta" reflectem sobre espectáculos do Teatro da Rainha, do Bando, do Teatro Nacional S. João, d'As Boas Raparigas e das propostas mais experimentais da Mala Voadora e da Sensurround, desta forma interpelando as criações cénicas de Fernando Mora Ramos, João Brites, Nuno Cardoso, Rogério de Carvalho, Jorge Andrade e Lúcia Sigalho. A elas se acrescentou ainda a que Mark Ravenhill trouxe, como autor e intérprete, a Lisboa. Pelo lado das produções editoriais, as "Leituras" inserem a lista do que se publicou em Portugal em 2005, entre textos de teatro - originais, reedições e traduções -, bem como estudos e documentos, para além de títulos de periódicos, o que vem sendo prática da Sinais de cena no número que sai em Junho (e a que se vem acrescentando em adenda o que pode ter escapado no recenseamento feito no ano anterior). Mas a secção introduz ainda reflexões críticas sobre uma peça recente, recensões de um manual de literatura, bem como de monografias que, nos dois casos assinalados, surgem como partindo de dissertações apresentadas no âmbito dos Estudos de Teatro, assim provando as boas razões que vêm norteando o esforço que se vai fazendo na Faculdade de Letras de Lisboa (entre outras instituições de ensino superior) para suprir o imenso atraso em que se encontra entre nós o teatro enquanto matéria de análise e reflexão.

É ainda consequência dessa atenção a quem faz e estuda o teatro que cabe destacar o livro que recentemente Eugénia Vasques dedicou ao encenador, actor e professor João Mota, enquanto pedagogo (João Mota, o pedagogo teatral: Método e criação, Lisboa, ESTC / Colibri, 2006) bem como o artigo sobre Raúl Solnado que Ana de Carvalho assina aqui para o nosso "Arquivo solto" (corolário da sua tese de mestrado apresentada à Faculdade de Letras de Lisboa). E, em tempo de celebrações e memórias, difícil é esquecer quem recentemente nos deixou para sempre mais sozinhos no teatro: Artur Ramos, Natércia Campos, Glicinia Quartin e Isabel de Castro. Foi, então, à memoria desta actriz (sobre quem Luis Rizo fez - parcialmente - a sua tese de mestrado, na Faculdade de Letras de Lisboa) que foi dedicado o espectáculo A mais velha profissão, que Fernanda Lapa encenou de maneira brilhante para o Teatro Nacional (com a colaboração d'As Boas Raparigas) e que as grandes actrizes Fernanda Montemor, Glória de Matos, Lia Gama, Lurdes Norberto e Maria José oficiaram de forma comovente e encantadora. Sinais sem dúvida do seu grande talento enquanto actrizes que ainda têm muito para nos oferecer, mas também sinal de uma razão cénica que identificamos como marca inconfundivel da encenadora Fernanda Lapa que nos concedeu a entrevista - a vários títulos interessante e valiosa - que anima a secção "Na primeira pessoa".

Para ela, como para todos os que continuadamente nos vêm apoiando - com informações, documentos, fotografias, apoios múltiplos - vão os "protestos" da nossa mais sincera gratidão. Porque esses apoios, sempre pacientes e preciosos, são indispensáveis pontos axiais para algumas das intermitências da razão que nos fazem mover. 